\title{
No more fish in the sea
}

\author{
The End of the Line \\ by Charles Clover. Documentary directed \\ by Rupert Murray \\ See http://endoftheline.com
}

So Long, and Thanks for All the Fish: the quirky title of Douglas Adams's novel could turn out to be visionary. Our rampant exploitation of the oceans is such that by 2048 we may be bereft of our favourite fish, leaving us to harvest less tasty creatures. This is the message clearly conveyed in The End of the Line, a documentary starring environmental journalist Charles Clover, based on his book of the same name.

The film takes narrator Ted Danson, an actor who co-founded Oceana, one of the world's largest ocean-conservation organizations, from the North Sea to the coast of Senegal where humans are fishing species to the brink of extinction. If history has a lesson, it is that once we have gone too far, there may be no turning back. Despite a moratorium on cod fishing in Canadian waters since 1992, the stock has shown little sign of recovery there. Now, European cod stocks and numerous other fish species worldwide face the same fate, owing to a combination of technological efficiency and ineffectual policy.

Clover popularizes the work of fisheries scientists, such as Daniel Pauly, a marine biologist at the University of British Columbia in Vancouver, Canada, who have pieced together a picture of imminent catastrophe in the

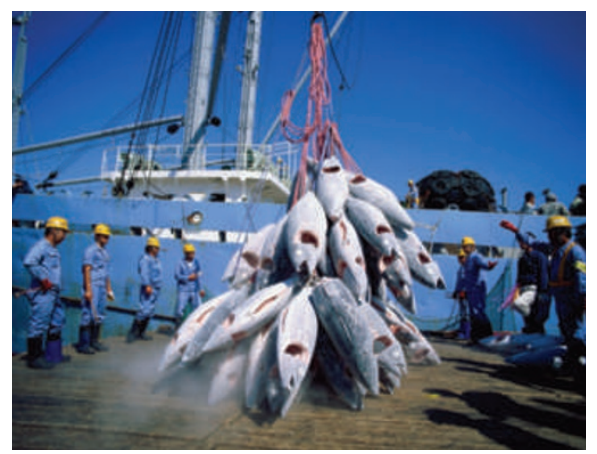

Frozen stocks may soon be the sole supply of tuna.

global ocean. Among the first to recognize that fisheries' catch rates were in decline worldwide, Pauly discovered in 2001 that the phenomenon had previously gone unnoticed owing to systematic distortions in catch trends that were skewed by incorrect reports from countries with big fisheries. In 2003, Boris Worm and Ransom Myers of Dalhousie University in Halifax, Nova Scotia, reported that $90 \%$ of all large fish - including tuna, swordfish, marlin and cod - had been removed from the ocean since 1950.

The End of the Line is informative. Clover's reporting reveals that bluefin tuna - the endangered species with perhaps the most alarming plight in the ocean - is allegedly being bought and frozen in bulk by major corporations. Once ocean supplies run dry, the frozen fish could be sold at sky-high prices.

Clover's portrayal of the global fisheries problem falls down on two counts: oversimplification and polarization. Although current fisheries policy is inadequate, much of it is based on science. Clover suggests, for example, that the practice of discarding - by which some 7 million tonnes of caught fish are thrown back into the sea each year - has arisen because fishermen simply do not want the species they have caught. But wasteful discarding is more often the consequence of a fisheries policy that is designed to prevent fishermen targeting juveniles and species outside of their allotted quota.

Clover is quick to point out the culprits of the fisheries crisis - slippery politicians, greedy fisherman, thoughtless consumers and big business - while making activists and scientists the stars of the show. But in adopting a tone of advocacy, with its inherent moralism, Clover isolates viewers and misses an opportunity to place this problem in context.

Overexploitation of fisheries is one part of the huge dilemma that humans face in an increasingly resource-limited world. We can seek sustainability, but we will not be able to diversify our consumption indefinitely. And climate change will decrease marine resources further. Those most affected will be the fisherfolk of developing countries, who make up $98 \%$ of people who are directly dependent on fisheries for their livelihood.

Despite its polemic hue, The End of the Line is an emotive portrayal of one of humanity's greatest challenges, and a stark reminder that early and effective action can make a difference. Olive Heffernan is editor of Nature Reports Climate Change.

\section{An eye for evidence}

\author{
The Scene of the Crime: \\ Rodolphe A. Reiss (1875-1929) \\ Elysée Museum, Lausanne, Switzerland \\ Until 25 October
}

To mark its centenary, the Institute of Scientific Police at the University of Lausanne, Switzerland, has released from its archives 120 crime-related photographs taken by its founder, a pioneer of forensic photography called Rodolphe Archibald Reiss. Now on show in Lausanne's Elysée Museum (Musée de l'Elysée), the exhibition comes with a warning: it is not suitable for sensitive people or children under 14.

In popular television series, the victims of murder tend to look reassuringly healthy.
But real death is unmistakable. It is both awe-inspiring and banal, and in this collection, often gruesome. There are images of the decapitated corpse of a man that was retrieved from the Lausanne-Geneva railway, along with his head; the exsanguinated body of a woman who botched a home abortion; and the old woman who was attacked so violently with an axe that her false teeth flew out, landing some distance away.

Few of the cadavers pictured are identified. The curators want you to look at them as Reiss did - objectively, with the aim of extracting the maximum information about the perpetrator and the circumstances of the crime. As for motive, you are left in the dark. Because the photograph is your only source of information, you enter into it fully, taking in every detail. In doing so, you cannot help but notice the misery of the conditions in which almost all of these crimes were committed.

The French criminologist Alphonse Bertillon is usually credited with turning the haphazard practice of forensic photography into a systematic science in the late nineteenth century. But it was his younger colleague Reiss who developed and disseminated those methods, and who founded the world-renowned institute in Lausanne. Reiss helped to establish scientific police services in Russia and Brazil, and in 1914, he became the Serbian government's official investigator into the atrocities committed by the German and Austrian armies in the First World War. A contemporary wrote that he would have made an excellent model for Sherlock Holmes: tall and youthful well into his fifties, he had eyes that shone with intelligence, and a passion for deciphering signs and traces.

Unlike fictional detective work, however, 